\title{
INTERACCION GENICA EN EL COLOR DEL PELAJE DEL HAMSTER SIRIO
}

GUILLERMO LLERENA (1) HUGO GONZALES-FIGUEROA(2)

(1)Laboratorio de Biología Celular U.N.M.S.M (2)Laboratorio de Biología del Desarrollo. Universidad Ricardo Palma

\section{RESUMEN}

Se describe un caso de interacción génica por reversión del color de pelaje del hamster sirio. Se cruzaron parentales blanco acromeliano y gris oscuro, obteniéndose en la $\mathrm{F}_{1}$ animales con pelaje tipo agutí y en la $\mathrm{F}_{2}$ se obtuvo cuatro mutantes para el color del pelaje. Se discute la importancia de la serie $C$, y no se descarta la existencia de una interacción epistática entre el pelaje gris y el blanco acromeliano.

PALABRAS CLAVES: Reversión de color, interacción epistática, hamster.

\section{SUMMARY}

A gene interaction case with coat color revertion in the syrian hamster is described. Dark gray and acromelanic white animals were mated; agouty type animals are found in the first generation $\left(\mathrm{F}_{1}\right)$ and four coat color mutants in second generation $\left(\mathrm{F}_{2}\right)$. The importance of the serie $\mathrm{C}$ is discussed and the existence of a epistatic interaction between dark gray and acromelanic white hamster is not descarted.

KEY WORDS: Color revertion, epistatic interaction, hamster.

\section{INTRODUCCION}

El color de pelaje del hamster sirio es un excelente marcador para establecer líneas genéticas diferenciales, que puedan usarse en la investigación biomédica.

Está plenamente comprobado que las mutaciones en el color de pelaje del hamster sirio, se asocian con anormalidades urogenitales (Fote,1955), microftalmia (Hughes \& Geeraets, 1962), con genes letales (Nixon \& Connelly, 1967; Nixon et al., 1969) y genes letales ligados al sexo. Se han reportado además, mutaciones que afectan el sistema nervioso (Nixon \& Connelly,1968; Yoon \& Slaney,1972), y que inducen la caida del pelaje (Nixon, 1972; Schimke et al.,1974; Festing \& Wright,1972).

Así mismo, se ha descrito el establecimiento de cinco grupos de ligamiento en el hamster sirio (Yoon et al., 1980)

En este trabajo, se reporta una interacción con reversión génica entre algunos genes que determinan el color del pelaje en el hamster sirio.

Los progenitores usados (Fig. 1), son los mutantes gris oscuro (Nixon \& Connely, 1969) y blanco acromeliano (Robinson, 1957).

Se analizaron 20 camadas, seis de ellas de la primera generación ( 48 individuos); 8 de la segunda generación (62 individuos) y 6 de cruzamientos colaterales (44 individuos).
En la primera generación, se usaron como progenitores machos gris oscuros y hembras blanco acromelianas, obteniéndose, en todas las camadas descendientes, tipo agutí, lo que evidencia una interacción génica de reversión al color del pelaje.

Al cruzar animales tipo agutí, las crías fueron: 14 blancos acromelianos, 6 cremas y 3 gris oscuros. En la $\mathrm{F}_{2}$, la proporción encontrada diferente a la de 9:3:3:1, sugiere un modelo genético distinto al esperado (Tabla 1).

Tabla 1. Modelo Genético Esperado

\begin{tabular}{|c|c|c|}
\hline \multicolumn{2}{|c|}{ Generación } & Color de pelaje \\
\hline Parental: & $\begin{array}{l}+/+\mathrm{dg} / \mathrm{dg} \\
\mathrm{c}^{\mathrm{d} / \mathrm{c}^{\mathrm{d}}+/+}\end{array}$ & $\begin{array}{l}\text { Gris oscuro } \\
\text { Blanco acromeliano }\end{array}$ \\
\hline Filial $_{1}$ & $+/ \mathrm{c}^{\mathrm{d}}+/ \mathrm{dg}$ & Agutí \\
\hline Filial $_{2}$ & $\begin{array}{l}\text { (esperado) } \\
+I_{-}+/+(3) \\
+I_{-}+\mathrm{dg}(6) \\
+I_{-} \mathrm{dg} / \mathrm{dg}(3) \\
\mathrm{c}^{\mathrm{d} / \mathrm{c}^{\mathrm{d}} /} I_{-}(4)\end{array}$ & $\begin{array}{l}? \\
\text { Agutí } \\
\text { Gris oscuro } \\
\text { Blanco acromeliano }\end{array}$ \\
\hline
\end{tabular}

Los cruzamientos colaterales, se hicieron en dos series.

En la primera serie, se cruzaron machos gris oscuro con hembras agutí $\left(\mathrm{F}_{1}\right)$ encontrándose en los descendientes individuos: agutí, gris oscuro y blancos acromelianos.

En la segunda serie los blancos acromelianos se aparearon con las hembras agutí y se obtuvieron individuos agutí y blancos acromelianos. 
Considerando que los colores gris oscuro y blanco acromeliano son mutaciones recesivas autosómicas (Yoon, 1973), se encuentra una segregación independiente y una dominancia incompleta del tipo agutí sobre las otras mutaciones recesivas. Por otro lado, el genotipo gris oscuro (dg/dg), no se expresa en el blanco acromeliano ( $\mathrm{c}^{\mathrm{d}}$ $c^{d}$ ), propio de la epistasis del blanco (Nixon et al., 1970).

La serie C, descrita para la herencia del color de pelaje en muchos mamíferos, incluyendo al hamster, es una seire de alelos múltiples.

El alelo dominante es necesario para la expresión de algún color de pelaje. Este alelo dominante, esta presente en el tipo agutí y en todos los animales pigmentados: gris oscuro y otros colores (Searle, 1968). Por consiguiente, la mitad o un poco mas de los decendientes de una cruza entre gris oscuro y blanco acromeliano serán siempre pigmentados.

No descartamos la expresión de una interacción epistática si consideramos que la condición homocigótica recesiva ( $\mathrm{c}^{\mathrm{d}}$ $\left.c^{d}\right)$ podría enmascarar otros genes que afectan el color del pelaje en el hamster sirio.

Por otro lado, la condición heterocigótica en la serie $\mathrm{C}$, es muy importante para la pigmentación del pelaje y detrmina la proporción de estos en la $F_{1}$. Nuestros resultados muestran una evidente expresión en el cruzamiento entre animales gris oscuro y blanco acromeliano, que se expresa como una reversión génica al color del pelaje. Asumimos que las hembras acromelianas de la generación parental, en este experimeto, son de tipo $\mathrm{c}^{\mathrm{d} d} \mathrm{c}^{\mathrm{d}}+/+$.

Si fueran homocigotes doblemente recesivas, los animales pigmentados en $\mathrm{F}_{1}$ podrían ser gris oscuro y si fueran heterocigotas no podríamos encontrar un tipo único en las crías.

Tabla 2. Cruzamiento Colaterales

\begin{tabular}{|c|c|}
\hline Generacion Parental & Generación filial \\
\hline $\begin{array}{l}\text { I.gris oscuro (dg/dg) } \\
\text { agutí (W_t) }\end{array}$ & $\begin{array}{l}\text { I-1. dg/dg (5), W_t (6) } \\
\text { I-2. dg/dg (4), W_t (2) } \\
c^{d} / c^{d}(1) \\
\text { I-3. dg/dg (1), } c^{d} / c^{d}(2)\end{array}$ \\
\hline $\begin{array}{l}\text { II.blanco acromeliano } c^{d} / c^{d} \\
\text { agutí }\left(W_{-} t\right)\end{array}$ & $\begin{array}{l}\text { II-1. W_t (6) } \\
\text { II-2. W_t (3), } c^{d} / c^{d}(3) \\
\text { II-3. W_t (6), } c^{d} / c^{d}(5)\end{array}$ \\
\hline
\end{tabular}

La posibilidad que los animales: gris oscuro y blanco acromeliano tengan una interacción independiente con el agutí se explica por los cruzamientos colaterales ( Tabla 2) Los animales gris oscuro y blanco acromeliano podrían estar en un grupo de ligamiento. Esta consideración podría evaluarse mediante un análisis único, de chi cuadrado en la $\mathrm{F}_{2}$, con el gen parental en acoplamiento $\left(++/ \mathrm{c}^{\mathrm{d}} \mathrm{dg}\right) \mathrm{y}$ repulsión $\left(+\mathrm{dg} / \mathrm{c}^{\mathrm{d}}+\right)$ respectivamente.

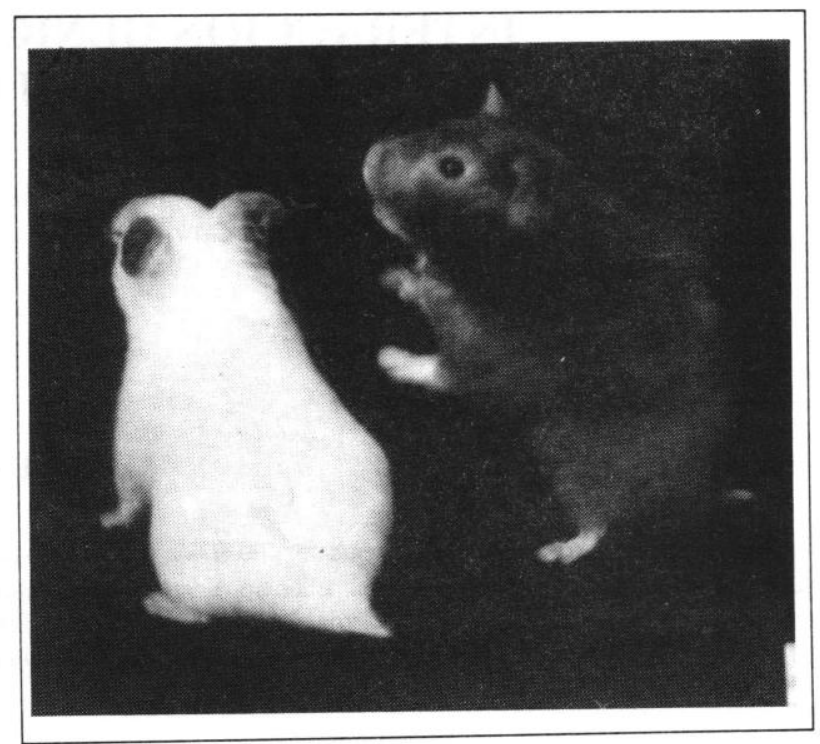

Figura 1. Hamsters gris oscuro y blanco acromeliano

\section{REFERENCIAS BIBLIOGRÁFICAS}

FESTING, M.F. \& WRIGHT M.K. 1972. New semidominant mutation in the syrian hamster. Nature 236: $81-82$

HUGHES, R.D. \& GEERATES W.J. 1962. Extreme microphtalmia in the syrian hamster. Genetics 4: 962.

NIXON, C.W., \& CONNELLY, M.E. 1967. Dark gray and lethal gray-two new coat color mutations in the syrian hamsters. Journal of Heredity 58: 295-296

NIXON, c.w \& CONNELLY, M.E. 1968. Hind-leg paralysis: A new sex linked mutation in the syrian hamster. Journal of Heredity 59: 276-278.

NIXON,C.W., WHITNEY, R., BEAUMONT. J.H. \& CONNELLY, M.E. 1969. Dominant spotting: a new mutation in the syrian hamsters. Journal of Heredity 60: 74

NIXON,C.W. 1972. Hereditary hairlessness in the syrian golden hamster. Journal of Heredity 63: 215-217.

ROBINSON, R. 1957. Partial albinism in the syrian hamster. Nature 180: 443-444

SCHIMKE, D.J., NIXON, C.W. \& CONNELLY, M.E. 1974. Long hair growth influenced by sex in the syrian hamster. Journal of Heredity 65: 57-58

YOON, C.H. \& SLANEY,J. 1972. Hydrocephalus: A new mutation in the syrian golden hamster. Journal of Heredity 63: 344-346

YOON, C.H., GROOT, C.T. \& PETERSON, J.S. 1980 Linkage relantionship of cardiomyopathy in the syrian hamster. Journal of Heredity 71: 61-62. 